\title{
A PANDEMIA COVID-19 E O TELETRABALHO NA PREVIDÊNCIA SOCIAL (PS)
}

\author{
Edvânia Ângela de Souza *
}

\begin{abstract}
Há um fato muito significativo que transfere o trabalho das instituições públicas e privadas para os espaços domésticos, que é a pandemia causada pelo novo coronavírus, Covid-19. Medidas de enfrentamento à pandemia preveem o distanciamento social, portanto, o trabalho vem sendo realizado de forma remota, todavia, a sua manifestação antecede à pandemia e vincula-se ao desenvolvimento tecnológico e às medidas neoliberais. Objetiva-se discutir o trabalho remoto na Previdência Social (PS) no Brasil. Foram realizadas entrevistas semiestruturadas com analistas de seguro social da PS. Evidencia-se que o teletrabalho resulta de um processo dialético, que implica na maior flexibilidade do horário de trabalho e, paradoxalmente, na ausência de condições adequadas, numa equação de elevada demanda, poucos trabalhadorela(s), exigência de cumprimento de metas, responsabilidade pelas condições adequadas para o trabalho realizado em casa, individualização e, em consequência, maior sobrecarga laboral, estresse e sofrimento mental relacionada ao trabalho.
\end{abstract}

Palavras Chave: Covid-19. Teletrabalho. Previdência social. Saúde dola trabalhadorla.

\section{INTRODUÇÃO}

Pensar a problemática do teletrabalho exige, necessariamente, pensar as transformações tecnológicas que ganharam visibilidade a partir da pandemia do novo Coronavírus, COVID-19. Diante da necessidade do isolamento social, o trabalho, em muitos casos, foi transferido para o espaço doméstico, na modalidade de home office e de teletrabalho. No caso da Previdência Social (PS), objeto de discussão desse texto, houve a ampliação do teletrabalho, acompanhado das plataformas de acesso aos benefícios previdenciários em rede de internet, são implicações derivadas das inovações tecnológicas em curso, que não surgem com a pandemia de COVID-19, mas que a partir dessa profunda crise sanitária foram impulsionados e adotados pelos setores públicos e privados.

Portanto, busca-se discutir a reorganização do trabalho e o acesso à Previdência

* Universidade Estadual Paulista (UNESP-Franca). Faculdade de Ciências Humanas e Sociais (FCHS).

Av. Eufrásia Monteiro Petráglia, n. 900, Jd. Dr. Antonio Petráglia. Cep: 14.409-160. Franca - São Paulo - Brasil.

edvaniaangela@hotmail.com

https://orcid.org/0000-0002-8997-7592
Social (PS), no Brasil, a partir da pandemia de COVID-19. Para esta análise consideram-se dois movimentos: 1) os discursos negacionistas, opondo-se, rigidamente, às exigências de prevenção e de enfrentamento à pandemia de COVID-19 e 2) a expansão do uso e interação com os meios digitais e Tecnologias da Informação e Comunicação (TIC), com ampla transposição do trabalho e os negócios para o ciberespaço, com ênfase fundamental da discussão para o teletrabalho e o acesso on line aos benefícios da PS brasileira, a partir da pandemia de COVID-19.

\section{MÉTODO}

O presente texto compõe um projeto de pesquisa mais amplo ${ }^{1}$, com resultados par-

${ }^{1}$ Este texto é parte de um projeto de pesquisa que visa discutir as condições de trabalho e saúde de assistentes sociais que atuam na seguridade social no Brasil. O projeto conta com a participação de pesquisadores e pesquisadoras de três universidades públicas: Faculdade de Ciências Humanas e Sociais (Unesp-Franca), Universidade Federal do Pará (UFPA) e Universidade Federal do Rio Grande do Sul (UFRGS), sendo as respectivas coordenadoras de cada região as professoras doutoras Edvânia Ângela de Souza (Unesp-Franca), Vera Gomes, Daniela Castilho, Welson Cardoso (UFPA), Jussara Mendes, Dolores Sanches Wünsch 
ciais publicados (Lourenço et al, 2019; Souza, Anunciação, 2020; Souza, 2021). Objetiva-se discutir as mudanças ocorridas na Previdência Social (PS) a partir da pandemia de COVID-19, com ênfase para a compreensão dos processos informatizados de acesso aos benefícios previdenciários e de trabalho remoto. Para tanto utiliza-se da abordagem metodológica qualitativa, por meio da realização de uma Oficina e uma entrevista semiestruturada, na forma de Grupo Focal (GF), com assistentes sociais (AS) da PS [contratadas como analistas de seguro social] . A Oficina foi realizada na modalidade presencial e contou com a participação de uma média de 20 AS de uma Gerência da PS do interior do estado de São Paulo, em dois dias consecutivos, ocorridos em outubro de 2017 e o GF ocorreu durante a pandemia de COVID-19, em agosto de 2020, por meio de plataforma virtual (sistema meet) e contou com a participação de quatro AS de uma Gerência da PS próxima à capital paulista. A coleta de dados ocorreu a partir de técnicas e em momentos diferentes o que somente foi possível por se tratar de um projeto de pesquisa em andamento. Salienta-se que com a pandemia de COVID-19 e respectivas medidas de isolamento social, avaliou-se a necessidade da realização de nova entrevista para compreender o processo de reorganização do trabalho e de acesso aos benefícios previdenciários. Durante a Oficina, ocorrida em 2017, AS já tinham enfatizado que a PS ปี estava reestruturando o atendimento e o trabalho a partir de plataformas na internet, assim, com as medidas de isolamento social, houve o aprofundamento da interação com os meios digitais, portanto, buscou-se compreender esse $\therefore$ processo no cotidiano de AS na PS. Para garanî tia de sigilo, utiliza-se o nome de flores para referenciar a autoria das informações coletadas e selecionadas para esse texto.

e Tatiana Reidel (UFRGS). Este projeto também fez parte das atividades de pós-doutorado, desenvolvido no perí-

I odo de 2015 a 2017 no Programa de Pós-Graduação em

Saúde Coletiva da Unifesp, sob a supervisão do Prof. Dr.

Francisco Antonio de Castro Lacaz. Ademais, foi aprovado

pelo CNPq, conforme Processo no 445443/2015-4, 2015-7

e, atualmente, na modalidade Bolsa Produtividade (PQ), sob o no $313708 / 2018$.

\section{A PANDEMIA DO NOVO CORONAVÍ- RUS, COVID-19 E A BANALIZAÇÃO DO MAL: entre o reconhecimento e a negação}

Nos dias que correm, fins de agosto de 2020, sociedades mundiais foram despertadas por uma grande ameaça à vida e, em consequência, à economia. A pandemia do novo coronavírus, COVID-19, inicialmente, afetou os países da Europa, mas já no mês de maio de 2020, a região das Américas assumiu o epicentro da doença, especialmente os Estados Unidos da América (EUA) (primeiro lugar), seguido pelo Brasil (segundo lugar) com a maioria dos casos (Brasil, 2020a).

A capacidade de responder à pandemia do novo coronavírus, COVID-19, apresenta inúmeros desafios, que inclui a potencialidade econômica, social, científica, cultural e ideológica presente nos vários países. De antemão é necessária a consideração quanto a organização da política de saúde, inclusive a sua capacidade de atendimento em unidades de terapia intensiva, pois, a COVID-19 tem apresentado alta e moderada taxa de fatalidade (Amitrano; Magalhães; Silva, 2020). É evidente que toda ação não deve se restringir à assistência hospitalar, mas é necessário calcular, acompanhar e interromper a circulação do vírus e isso se faz com serviços de atenção básica e de vigilância em saúde (sanitária, epidemiológica e ambiental) (Who, 2020). Em decorrência da ausência de vacinas aprovadas e prontas para uso, em agosto de 2020, tratamentos farmacológicos específicos para o tratamento de COVID-19 e da alta transmissibilidade do vírus e das taxas de fatalidade, as medidas adotadas incluem, sobretudo, o distanciamento social (Amitrano; Magalhães; Silva, 2020). Os autores evidenciam que os países europeus, a partir das medidas de distanciamento social até a adoção do lockdown, reduziram as taxas de fatalidades da COVID-19 (Amitrano; Magalhães; Silva, 2020). Países como Espanha e Reino Unido que vinham reproduzindo a política neoliberal, 
neste período, mobilizaram até $20 \%$ do PIB em medidas de enfrentamento da crise econômica (Amitrano; Magalhães; Silva, 2020).

Aqui, não se pode negar que os EUA assumem a posição de Estado Imperialista do sistema d'Capital, todavia, é onde também os ideais quase canônicos do neoliberalismo de Regan (Anderson, 1995) foram ditados e colocados como regras a serem seguidas pelos demais países. Nos Estados Unidos, até agosto de 2020, os registros relativos à pandemia do novo coronavírus, COVID-19, têm sido feitos com atrasos de semanas ou até mês (Shumaker; Chiacu, 2020). Os EUA possuem mais cinco milhões de infectados e a cifra de número acumulado de óbitos de 181.773, em 22 de agosto de 2020 (Brasil, 2020a, Who, 2020).

É possível verificar comportamentos, dualisticamente excludentes, de um lado, a contestação da doença; de outro, o medo, o pavor ou até mesmo a histeria frente ao vírus, em reação, geram-se comportamentos que passam pela adaptabilidade até a leviandade elou a xenofobia. A negação da importância ou da letalidade da pandemia do novo coronavírus, COVID-19, tem produzido narrativas e comportamentos que desviam a atenção do que é essencial: o enfrentamento com responsabilidade desse grande problema sanitário que avassala famílias e economias inteiras.

Neste cenário têm sobressaído as narrativas que visam desconsiderar a fatalidade do vírus, como a fala do presidente Donald Trump que afirmou que 99\% dos casos de coronavírus nos EUA eram inofensivos, conforme matéria de Reuters, de 07 de julho de 2020 (Shumaker; Chiacu, 2020). Isso, decerto, enfraquece em muito as medidas de prevenção do novo coronavírus e afasta governos e imaginário social da legitima problemática, para assumir o viés da negação do vírus e das respectivas medidas de prevenção. Além disso, discursos marcados pela polarização política, posicionamentos contrários às instituições componentes dos Estados Democráticos e até mesmo contrários à Organização Mundial da Saúde (OMS), como os que têm sido feitos pelo presidente dos EUA, Donald Trump e seguido, entre outros, pelo presidente brasileiro, Jair Bolsonaro (sem partido) (Coletta, 2020) desviam a atenção das medidas de enfrentamento à pandemia e reforçam teorias negacionistas e de conspiração. Em resultado, verifica-se a ausência de engajamentos profícuos de governos em comitês capazes de buscar saídas para a crise sanitária e econômica.

A deliberada ausência da intermediação científica está acompanhada dos discursos de ódio, de intolerância política, religiosa, étnica, sexual, geopolítica e de notícias falsas, fake news, como se pode exemplificar com os posicionamentos acerca da pandemia de COVID-19 em alguns países. Na Índia, foi espalhado deliberadamente que o vírus era culpa dos muçulmanos, "como uma forma de jihad" (Roy, 2020, sp). Na Nicarágua, o governo não apenas retardou as medidas de contenção do vírus como insultou o povo a sair nas ruas em nome de Deus, promovendo caminhadas, com o lema "Caminhamos com a força da fé e da esperança, com amor nos tempos da COVID-19” (Miranda, 2020, sp.). Nos EUA, Donald Trump usou o termo "vírus chinês" (Fellet, 2020), seguido no contexto brasileiro por Eduardo Bolsonaro (Colon, 2020). Tal fato gerou profundo mal-estar entre os dois países, Brasil e China, cuja relação já havia sido abalada com a visita do presidente Bolsonaro a Taiwan, em 2019 (Fellet, 2020).

A razão dessa exposição evidencia que além do novo coronavírus, COVID-19 e seus danos específicos e colaterais, há ainda que considerar o vírus ideológico da ignorância: "La propagación continua de la epidemia de coronavirus también ha desencadenado grandes epidemias de virus ideológicos que estaban latentes en nuestras sociedades: noticias falsas, teorías de conspiración paranoicas, explosiones de racismo" (Zizek, 2020, p.21).

O negacionismo da ciência em tempos de pandemia de COVID-19, resguardada as devidas proporções, comparece na narrativa literária desenvolvida por Camus (2014). Como sensibilizar 
as pessoas ante uma pandemia, uma vez que as mortes ficam espalhadas ao longo dos tempos, portanto, esse distanciamento tendencialmente esfumaça o problema na imaginação de ampla maioria das pessoas (Camus, 2014). Deriva desse processo as posturas que podem dificultar o reconhecimento da pandemia enquanto problema, portanto, em nome da "normalidade" das atividades econômicas, disseminam falsas notícias, que situam a causa da pandemia em grupos étnicos historicamente marginalizados, em forças sobrenaturais e, até mesmo, como passageira ou como se o vírus tivesse um ciclo natural de propagação, que surge e se extingue sem que sejam necessárias a adoção de medidas drásticas ao seu enfrentamento.

Nesse compêndio de negacionismo da ciência, teorias conspiratórias e de falsas informações (fake News) não se tocam nas causas reais da pandemia, as quais se vinculam à questão ecológica, ao agronegócio e à evolução de patógenos humanos a partir da indústria de carnes, especialmente, avícola e de suínos em grandes confinamentos e em economia globalizada (Wallace, 2020). Esse modo de produção vinculado à globalização econômica é capaz de levar, por exemplo, os vírus da gripe "aviária" e "gripe suína" para todo canto do mundo. A "gripe aviária” cujas cepas de influenza passaram a ser numeradas pela OMS, “[...] h5n1, a os outros sorotipos de influenza h5n2, h6n1, h7n2, h7n7, h9n2 - se alinham agora nas fazendas industriais como ciclones tropicais స్ no oceano" (Wallace, 2020, p. 33). A exportação ○- de carnes e também a exportação dos custos do trabalho e ambientais, uma vez que as indústrias agrícolas transferem a sua produção para países em desenvolvimento e de regulação mais flexível $\dot{2}$ ou até mesmo inexistente criam o rearranjo "huகீ mano-ave-suíno" responsáveis pelas epidemias de influenza (Wallace, 2020).

Ao negar pandemia de COVID-19 e a ciência, recria-se o pensamento e as narrativas conservadoras, autoritárias, violentas, conspiratórias e reacionárias, as quais têm se intensificando na sociedade brasileira. O discurso ideológico que desconsidera a ciência e que nega a pandemia, desestimula as medidas de isolamento social, em consequência, afeta, sobremaneira, a população empobrecida, especialmente, periférica e vinculada ao trabalho informal. Trata-se de um discurso que não sobrevive isoladamente, mas se junta, cresce e se propaga sem se embaraçar minimante com os dados oficiais das infecções ou números de mortes causados pela COVID-19, tampouco se embaraça com o sofrimento das famílias ou o risco de colapsar o sistema de saúde e economia.

No Brasil, a pandemia do novo coronavírus, como uma crônica de morte anunciada, já ceifou a vida de mais de 120 mil pessoas por COVID-19, até a Semana Epidemiológica n. 35 (23 a 29 de agosto de 2020 (Brasil, 2020a), afetando mais gravemente a população que sofre com a precarização do trabalho e a desigualdade social, com recortes de gênero e étnico-racial (Santos et. al., 2020).

Evidencia-se um processo de banalização da vida e do sofrimento, com narrativas e ações violentas, como a que um grupo de enfermeiras sofreu, ao protestar em frente ao Palácio do Planalto, no dia 10 de maio de 2020, dia do trabalho, contra as mortes e a falta de Equipamento de Proteção Individual (EPI) de profissionais da saúde (Machado, 2020). Outros exemplos podem ser simplificados nas carreatas e buzinaços, inclusive em frente aos hospitais de campanha construídos para o atendimento de pessoas contaminadas e com COVID-19 (Onofre; Garcia, 2020) e na exposição de um grupo de funcionárias que tiveram que se ajoelhar para uma determinada manifestação contra as medidas de isolamento social (Brasil de Fato, 2020).

O governo de Jair Bolsonaro (sem partido) se coloca contra às medidas de isolamento social, uso de máscaras, de vacinas e, paradoxalmente, saiu em defesa do "tratamento precoce" constituído, especialmente, do medicamento hidroxicloroquina, para o qual ele chegou até mesmo a posar como garoto-propaganda em um outdoor (Valfré e Soares, 2020).

O conceito "banalização do mal" advém das análises de Dejours (2006), que com maes- 
tria caracteriza o peculiar resultado do engajamento social, inclusive da classe trabalhadora, ao sistema econômico vigente, que destrói empregos e intensifica meios e métodos para cobrar mais trabalho daqueles que conseguem seguir trabalhando, o que gera um sofrimento social generalizado causado tanto pelo desemprego, quanto pela intensificação do trabalho dos que se mantém trabalhando. Todavia, esse sofrimento ecoa como uma causalidade do destino ou uma adversidade. Banalidade do mal remete inevitavelmente aos processos capitalistas atuais, com suas exacerbadas taxas de desigualdades sociais, afetando mais profundamente a população negra e as mulheres negras, mas a paródia é que o sofrimento se apresenta como uma questão destacada do sistema e do envolvimento e responsabilidade dos indivíduos que estão engajados para a maior eficácia do sistema d'Capital e, no contexto brasileiro, do próprio racismo estrutural e cultural (Gonzáles, 1984).

A contradição é que precisamente a pandemia não é um fenômeno simples, especialmente, em economia, porque é de vidas que se processam as relações sociais de produção e de consumo. Aqui, está em questão a produção do valor inteiramente ligado ao trabalho, por isso, obrigam-se o fim das medidas de isolamento social e, portanto, o retorno ao trabalho. Assim, se discursos pós-modernos, desde os anos de 1990, vinham enfatizando um suposto fim do trabalho ante as inovações tecnológicas, no atual contexto, evidenciou-se que o trabalho continua sendo a mola propulsora desse modo de produzir e de gerar o mais valor (Marx, 2006; Antunes, 2018).

O LUGAR DO TELETRABALHO NA PS: raízes nas inovações tecnológicas e neoliberalismo com expansão a partir da pandemia de COVID-19

Admite-se que o teletrabalho não pode ser analisado de forma destacada da totalidade social, pois antes de se limitar à expansão das tendências tecnológicas durante a pandemia de COVID-19, deve ser considerada a historicidade do desenvolvimento do capital, perpassando por suas crises, reestruturação produtiva, neoliberalismo, globalização econômica e ampla expansão do poder do capital, que vem ocorrendo, em grande medida, a partir dos investimentos maciços em novas tecnologias.

A partir da pandemia de COVID-19 tornaram-se mais evidentes os processos que vem sendo classificados como partes da $4^{\mathrm{a}} \mathrm{Re}-$ volução Industrial ( $4^{\mathrm{a}} \mathrm{RI}$ ), com a integração dos sistemas físicos com os meios digitais, internet avançada, ampla digitalização da indústria, dos serviços e da economia em geral (Schwab, 2016).

Com a pandemia de COVID-19, projetos de rastreamento das pessoas, para indicar a locomoção em tempos de isolamento social ganharam visibilidade (SP Contra, 2020). Mas tal possibilidade não é uma ação isolada. Cotidianamente um volume incomensurável de dados está sendo criado voluntariamente pelas pessoas que acessam os vários sistemas, redes sociais, compras on line, buscas variadas e inclusive acesso às plataformas de governo e de políticas sociais e públicas. Quanto ao destino desses dados não se tem conhecimento e tampouco autonomia sobre eles. Trata-se de uma mudança estrutural que não está limitada a transferência do trabalho para os espaços externos às empresas, mediados por sistemas de informática, ainda que o teletrabalho seja uma mudança radical na estrutura do trabalho, considerando a sua organização, gestão e solidariedade de classe, mas não se resume a essas questões. A tramitação de todas as operações para o ambiente virtual permite a extração, análise e monitoramento de dados e maior vigilância e controle. São imensos fluxos de informações que são passíveis de verificações e de compartilhamento, é a Big Data, segundo a lógica da acumulação capitalista, com profundas consequências para o capitalismo de vigilância (Zuboff, 2018). 
A automatização não se limita ao espaço fabril, mas ganhou proporções inimagináveis, com a conexão entre objetos, Internet das Coisas (IoT), Big Data, robótica, nanotecnologia, bioengenharia, criogenia, entre outros (Fernandes, 2019). Robôs digitais, Inteligência Artificial (IA), substituem muitas atividades até então exercidas por humanos e as empresas investem, cada vez mais, nos meios digitais; a própria PS vem reestruturando o trabalho e o atendimento ao público a partir de softwares para interação de usuários e usuárias com o sistema previdenciário on line "[...] hoje, se você acessar o site Meu INSS, tem uma assistente virtual para dúvidas” (Rosa, GF, AS/PS, 2020).

O teletrabalho é o trabalho fora da Agência, é o trabalho em casa, que com o seu notebook você pode ter acesso a todos os sistemas, ainda é muito piloto. O INSS digital é isso, é uma forma de você não comparecer na Agência, mas acessar o seu benefício da sua casa ou de outro lugar. O Meu INSS é o acesso on line, que as pessoas podem fazer. Então, você envia os documentos eletronicamente, mas quem vai fazer isso? As pessoas que acessam o INSS têm condições? Os atravessadores e aqueles que estão imbuídos da função de procuradores, inclusive tem muita gente, advogados, batendo palmas para essa iniciativa. Isso começou o ano passado, já tinha esse debate, mas esse ano [2017] já está vindo como uma avalanche, como um rolo compressor, porque tem uma demanda muito grande de aposentadorias, praticamente metade do quadro de servidores do INSS, já têm tempo de se aposentar, talvez até por isso ainda não foi incorporada a gratificação no salário, సิ que nós conseguimos com a greve de 2015 (Narciso, กे Oficina, AS/PS, 2017).

PS, em 2017, o teletrabalho compareceu como 今 um projeto-piloto, como também o investi¿. mento em tecnologias digitais para o acesso में aos serviços e requerimentos de benefícios e $\vec{i}$ aposentadorias por meio de sistema on line, Meu INSS. Naquele momento, havia uma preocupação com as dificuldades que ampla maioria de usuários e usuárias teria para conseguir acessar os seus direitos, assim, a transferência do acesso físico para o digital poderia reivindicar atravessadores, ou seja, pessoas que cobram percentuais sobre os ganhos de quem busca por esse tipo de auxílio, imputando uma espécie de pedágio para o acesso ao direito. Penaliza-se assim essas frações da classe trabalhadora que já sofrem com as duras condições de vida, baixos ou ausentes rendimentos, além do analfabetismo, precárias condições materiais (computador e internet) e de habilidades para o acesso ao direito por meio de plataformas digitais. AS evidenciaram também que em muitos municípios podem ocorrer práticas de barganha política, tão comuns Brasil afora. Ademais, foi destacado que quase metade dos servidores e servidoras da PS estavam em vias de se aposentar, mas que tal fato ainda não havia ocorrido devido a não incorporação das gratificações no salário, conforme ganhos da greve ocorrida em 2015, portanto, uma conquista da categoria de trabalhadores e trabalhadoras da PS, que não foi implementada pelo governo federal.

$\mathrm{O}$ quadro insuficiente de servidores e servidoras e a não realização de concursos públicos na PS são razões que justificam e impõem o teletrabalho na PS, como vem se evidenciando mais profundamente nesse momento da pandemia de COVID- 19. Portanto, o teletrabalho se configura como um processo em curso, em razão da adoção da racionalidade neoliberal, que aprofunda a individuação social, a competitividade, a recusa aos direitos sociais e a democracia (Dardot; Laval, 2017).

Ao virtualizar o atendimento e o trabalho, a PS não demonstrou maiores preocupações com a unidade entre as condições de acesso e a capacidade de parte da população para acessar e compreender os sistemas virtuais: “[...] como se todos os segurados tivessem acesso à internet, sobretudo, o conhecimento e as condições necessárias para acessar as informações de forma independente" (Lírio, GF, AS/PS, 2020). Transferir o trabalho para ser feito em casa e por meios remotos por si só não significa garantir o acesso ao direito e aos serviços. Verifica-se a tônica dada pelo neoliberalismo - em alianças com as inovações tecnoló- 
gicas -, que é a tendência de eliminar direitos e aprofundar o individualismo e a satisfação de necessidades via mercado. Portanto, a transposição dos serviços físicos para o meio digital estabelece o vão entre usuários e usuárias e as Agências da Previdência Social (APS), o que significa a exclusão do malabarismo verbal e explicativo acerca do acesso ao direito, provocando um visível distanciamento desse.

O acesso aos benefícios assistenciais através dos meios digitais tem excluído parte da população, principalmente a mais carente e que não possui acesso à internet, ou até mesmo à linhas telefônicas. Identificamos outros problemas, como analfabetismo, dificuldade de entendimento do sistema, disponibilidade insuficiente de servidores para socialização de informações...” (Lírio, GF, AS/PS, 2020). A população usuária tem cada vez mais obstáculos no acesso aos direitos. Atualmente, inclusive o acesso à própria instituição tem sido restrito, com redução de horário de atendimento, agendamento por telefone 135 e transferência de uma série de serviços para os canais remotos. A concessão de benefícios assistenciais tem levado até oito meses, o que dificulta o acesso aos direitos sociais básicos (Bromélia, Oficina, AS/PS, 2017).

Eu acho que a mudança afeta os servidores em geral, não apenas os usuários, isso porque a gente se sente muito sozinha, trabalhando em casa, você vai discutir com quem? Se você tinha dúvidas, o que eu fazia? Eu ia lá e falava com quem estava na análise, nossa, era tão mais fácil, agora, eu nem sei quem faz análise, como faz, eu não tenho com quem discutir (Camélia, GF, AS/PS, 2020).

Os depoimentos indicam as dificuldades que a população usuária enfrenta para acessar os benefícios e direitos previdenciários; por um lado, antes mesmo das medidas de isolamento social necessárias para a contenção das contaminações por COVID-19, a PS já vinha investindo no complexo tecnológico digital, como o sistema on line, Meu INSS, os agendamento pelo número telefônico 135 e o projeto piloto para o teletrabalho; a partir da pandemia o meio digital comparece como tendência mundial para o trabalho, os serviços, os negócios e a vida social/afetiva, transformando estruturas e estratégias empresariais e de políticas sociais e públicas, bem como os processos de trabalho. $\mathrm{O}$ aspecto fundamental é que tais mudanças compõe as bases de competição internacional do capital e que vem sendo incrementadas ao longo do século XX e que emergem no contexto pandêmico como possibilidade de manter determinada "normalidade" do trabalho, dos negócios e da vida.

Esse complexo de questões se apoia no aprofundamento das medidas neoliberais. Assim, o teletrabalho na PS não pode ser analisado de forma isolada, independente ou como resultante unicamente da pandemia de COVID-19, embora tenha se intensificado a partir dela, o teletrabalho é parte do processo de inovações tecnológicas em que a força de trabalho se engaja de forma ativa, individual e com uma carga acentuada de responsabilidade para a operacionalização das atividades laborais por meio de plataformas digitais.

Observa-se que a PS foi caracterizada, durante as entrevistas, tanto pela Oficina realizada em 2017, quanto pelo GF em 2020, pelas constantes mudanças nos regramentos dos benefícios, acessos virtuais e implementação de estratégias de organização e gestão do trabalho a partir dos meios remotos e de produtividade, com vistas não apenas a obter o envolvimento nas metas estabelecidas, mas especialmente, na preparação para a maior rigidez das análises dos processos de pedidos de benefícios previdenciários, levando até mesmo ao reconhecimento que os funcionários e funcionárias da PS, em geral, não fazem a defesa da PS como política social pública.

Interessante, que na greve dos servidores em 2015, a população ficou do nosso lado. Foram feitas as informações necessárias da defasagem salarial e a greve contou com um apoio importante de parte da população. Logo depois, em 2016, quando começou a investida do governo contra a PS, com o projeto da contrarreforma, houve um silêncio muito grande... também quando o governo criou o "pente fino" dos benefícios, eliminando uma parte grande de quem tinha esse benefício, também houve silêncio dos servidores e servidoras (Crisântemo, Oficina, AS/ PS, 2017). 
Ao analisar o teletrabalho na PS, além de se enfatizar as inovações tecnológicas em voga, especialmente, a partir da $4^{a} \mathrm{RI}$ (Schwab, 2016), há de se reconhecer a conjuntura econômica, marcada pela crise do capital, amplamente aprofundado pela pandemia de COVID-19, mas que, ao menos desde 2008, vem exigindo dos Estados maior flexibilização das legislações sociais, trabalhistas e ambientais (Antunes, 2018). Portanto, o capital na sanha de recuperar as suas taxas de acumulação redesenha a "reestruturação econômica" articulada visceralmente à hegemonia neoliberal, a qual conta com a participação de quem também é por ela afetado, como os trabalhadores e trabalhadoras do setor público.

O cenário também é marcado pelo desemprego, com possíveis vagas de trabalho como prestação de serviços por meio de plataformas digitais, de entrega de mercadorias, compartilhamento de viagens e outras formas de trabalho por plataformas digitais (Abílio, 2019), acentuando a precarização do trabalho, com recebimento por atividades, sem quaisquer garantias, o que reverbera no aprofundamento do individualismo.

O teletrabalho foi caracterizado como um trabalho essencialmente individual. O trabalho desempenhado no coletivo e presencialmente suscita ações solidárias e também de resolutividade técnica das questões presentes no dia a dia de trabalho; já o teletrabalho atinge o $\vec{\delta}$ próprio processo de trabalho, que se torna fragऽ mentado, individualizado e muito marcado $\stackrel{\%}{\sigma}$ pela produtividade. Frisa-se que a convivência \& no cotidiano de trabalho possibilita vínculos $\stackrel{7}{7}$ interessantes, que muitas vezes não se limi¿. tam ao cotidiano profissional e avança para lafi ços de amizade e suporte social, todavia, é no

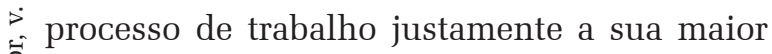
contribuição, porque permite o socorro socializado entre os trabalhadores e trabalhadoras para a realização de muitas tarefas, sendo esse apoio mútulo extremamente importante para a solidariedade de classe e também para a efetividade do trabalho real (Dejours, 1987).
Brevemente, é importante situar a definição de trabalho real e trabalho prescrito desenvolvida por Dejours (1987). O trabalho prescrito se trata do que já foi pensado e normatizado pela gestão, burocratizado e estabelecido por meio de um padrão a ser seguido e fiscalizado, mas é no cotidiano laboral, que o trabalhador e a trabalhadora enfrentam dificuldades e problemas variados para a execução desse trabalho, que foi prescrito anteriormente, mas que pode exigir maior atenção e envolvimento para a superação de eventuais dificuldades para a sua execução, sendo caracterizado por Dejours (1987), como trabalho real.

O trabalho em casa ou o teletrabalho segue um caminho sumário, desacompanhado da troca entre as equipes, portanto, se efetiva na distância com o trabalho coletivo, todavia, embora esteja deslocado do coletivo e assentado no solo individual e, na maioria das vezes, doméstico, mantém-se interligado ao trabalho coletivo por meio de fios invisíveis do sistema digital o que gera, entre outros, um sentimento de desencontro ou apartamento, em reação: “[...] a gente tem a sensação que está fazendo um trabalho ruim porque realmente a gente não consegue acompanhar isso... tem também as dificuldades de compreender as normativas, que são muitas e mudam muito" (Camélia, GF, AS/PS, 2020). O teletrabalho pode ser marcado pela insegurança devido à dificuldade de compreensão do sistema e ausência de trocas entre os trabalhadores e trabalhadoras, tal como é comum no ambiente presencial. Ou seja, além de ser um trabalho caracteristicamente individual e solitário, se torna mais complexo e difícil de ser operacionalizado devido a necessidade de acompanhar e, portanto, ter domínio das mudanças nas normas de acesso aos benefícios previdenciários.

Durante as entrevistas um traço fundamental que compareceu em muitos depoimentos é que o trabalho na PS tem uma dinâmica, quase rotineira, de mudanças de normativas e regulamentos. O INSS foi destacado pela sua gestão de muitas cobranças, mas de pouca preparação do seu quadro de trabalhadores e trabalhadoras 
para acompanhar as mudanças instituídas. Dessa forma, o trabalho coletivo e presencial nas Agências tem efeitos inegáveis para o desenvolvimento do trabalho real e proteção da saúde. "Essa insegurança vai gerando um adoecimento, eu, por exemplo, tenho dificuldade de ler normativas, às vezes, até de entender esses sistemas todos, isso nos impacta muito, adoece mesmo" (Camélia, GF, AS/PS, 2020).

O teletrabalho na PS está associado à ausência de concurso público e ao reduzido quadro de funcionários no INSS. Bem mais que isso, o teletrabalho se apresenta como alternativa à aposentadoria de quase metade dos servidores e servidoras e a introdução de um controle sobre o trabalho que fragmenta profundamente a categoria do setor público.

Frisa-se que não é a pandemia do novo coronavírus, COVID-19, que cria o teletrabalho, o qual tampouco subsiste como fenômeno isolado, mas advém de um processo pré-existente que, como já dito, se alinha às inovações tecnológicas empenhadas no processo da $4^{\mathrm{a}} \mathrm{RI}$ (Schwab, 2016) e às mudanças em torno dos direitos sociais, do trabalho e do papel do Estado, que atua plenamente conforme as diretivas neoliberais, inclusive da ausência de concursos públicos. Além disso, a atual política brasileira, em termos genéricos, tem regredido os direitos humanos e sociais , como também a própria democracia, para isso, utiliza, entre outros, de ampla militarização dos serviços públicos, especialmente cargos estratégicos "[...] em maio de 2020, nós tivemos a publicação da medida que autoriza a contratação de 8.230 servidores temporários, aposentados do INSS e militares inativos e também a contratação de 4.350 estagiários de nível superior e 2.343 estagiários de nível médio" (Rosa, GF, AS/PS, 2020). Essas informações podem ser conferidas na publicação da Portaria 10.736, de 2020, que autoriza a contratação temporária de trabalhadores e trabalhadoras aposentados pela PS e de militares, como temporários nas APS (Brasil, 2020b). O site da Secretaria de Previdência Social também apresenta a no- tícia da contratação de 8.230 servidores e servidoras, na condição de contratos temporários (Brasil, 2020c).

No que concerne à célula comum, a estrutura neoliberal, o governo federal praticou um corte fino, mas muito sofisticado, porque se coloca na posição de contratação de pessoal para atender a demanda que aguarda a análise de benefícios, e que está represada, portanto, atende uma necessidade social. Doravante essa atitude tem uma constância quase canônica do presidente Jair Bolsonaro (sem partido) em defender e privilegiar as Forças Armadas, por isso, abre a possibilidade de militares, estando em inatividade se inscreverem para concorrerem ao edital de contratação temporária, como previsto na Portaria 10.736 (Brasil, 2020b). Ao contratar inativos das Forças Armadas, aposentados e aposentadas da PS e estagiários e estagiárias sustenta a correspondência do Estado com o trabalho precarizado, que não realiza concurso público e que pouco contribui para a política de trabalho e renda no país, especialmente de combate ao desemprego. Reforça a aliança do Estado com o militarismo, autoritarismo e corrói a democracia.

\section{TELETRABALHO: entre o discurso do privilégio e a demanda por au- mento da produtividade}

O teletrabalho alinha-se ao processo de plasticidade da precarização ou uma composição de partes dessa precarização que avança sobre os serviços públicos, especialmente, da não realização de concursos públicos e de maior insegurança no trabalho, mas é apresentado de forma invertida: "O que eu tenho percebido é que quando o INSS passa a proposta do teletrabalho, ele faz como se fosse uma maravilha: "nossa, olha que beleza, você pode trabalhar em casa", como se fosse um privilégio (Girassol, GF, AS/PS, 2020). Ao situar o teletrabalho como privilégio transcende-se a ordem epistemológica do seu significado de 
transformações tecnológicas e aprofundamento do neoliberalismo.

A forma social do teletrabalho assumida a partir da particularidade da pandemia de COVID-19 foi (e é) a de medida necessária para conter a propagação do vírus. Todavia, esse é parte do movimento global do capital, extremamente financeirizado, globalizado e informatizado, com profundos impactos sobre o trabalho (Antunes, 2018; Abílio, 2019).

Se se considera que a taxa de desocupação, no trimestre de julho a agosto de 2020, chegou a $14,4 \%$, contra $12,9 \%$ no trimestre anterior e 11,8\% em agosto de 2019 (IBGE, 2020a) e a população desalentada totalizou 5,9 milhões de pessoas e teve um acréscimo de 440 mil pessoas, além da informalidade no trabalho que atingiu 31 milhões de trabalhadores e trabalhadoras, 38\% (IBGE, 2020a); estar trabalhando pode se manifestar como um privilégio na estrutura do atual mercado de trabalho e estar trabalhando de forma remota, em tempos de pandemia de COVID-19, pode se tornar um privilégio maior ainda.

O IBGE realizou uma pesquisa específica a respeito do teletrabalho com os seus funcionários e funcionárias, num total de 8.402 respondentes, correspondendo a uma participação de $72,5 \%$, sendo a quase totalidade de participantes de servidores e servidoras efetivas, 72,8\% (IBGE, 2020b).

No conjunto dos dados reportados, desiิ taca-se a positividade do teletrabalho indicaస da nas principais proposições: não precisar se O locomover para o trabalho; ter maior flexibili¿ dade do horário de trabalho; poder fazer o dis- tanciamento social; mais conforto em casa e a ¿. proximidade com a família (IBGE, 2020b), não ङ se teve notícias de eventual estudo do teletra-

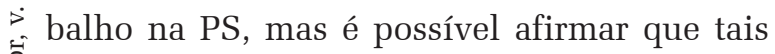
fatores também comparecem nos depoimentos obtidos por meio de entrevistas com AS da PS.

O trabalho remoto, em um período crítico, como é a pandemia de COVID-19, adquire um tom de emergência e de necessidade. Um traço peculiar é que ao possibilitar o trabalho em casa, feito remotamente, evita-se a aglomeração e fortalece as medidas de isolamento social necessárias para a contenção das contaminações do novo coronavírus. Porém, da totalidade da força de trabalho ocupada, apenas 7,9 milhões estão em trabalho remoto, em julho de 2020 (IBGE, 2020a). Assim, poder trabalhar em casa, sem expor ao vírus, se torna um privilégio ante às ocupações que não puderam sequer fazer isolamento social.

O ganho temporal ou a pretensa autonomia do uso do tempo, que supostamente coloca o teletrabalho como privilégio, pode se perder com as exigências institucionais para o cumprimento de metas e das condições de trabalho, como ter um lugar apropriado, condições objetivas e subjetivas para a execução do trabalho, conseguir separar os vários papeis assumidos na vida pessoal e na vida profissional, sobretudo, pela infusão da divisão sexual do trabalho (Nogueira, 2004), que impõem às mulheres o "dever" com as atividades domésticas, sobrecarregando as mulheres com dupla ou tripla jornada de trabalho.

Em casa, etimologicamente, é um termo de significado altamente relevante para a vida pessoal, constituinte do núcleo familiar, jamais como um elemento autônomo e isento de interferências e contradições variadas. Designa o lócus da vivência e da experiência afetiva e social, um lócus gelatinoso e muito conflituoso, mas vivo, ambivalente, donde procede a vida privada. Panela de pressão, cheiro de comida, casa suja, roupa para lavar, máquina batendo, roupa no varal, aluguel vencendo, latidos de cachorro, criança chorando, risadas, som alto, lição de casa, aulas on line, gato miando, campainha tocando, geladeira vazia, energia cortada, torneira seca, botijão de gás sem gás... são fluídos do termo "em casa” para não entrar nos aspectos mais subjetivos.

Nesta direção, a partir da pandemia de COVID-19 e respectivas medidas de isolamento social, com fechamentos de escolas, as mulheres foram severamente sobrecarregadas. A rigor a sociedade brasileira é determinada 
pelo poder de classe oligárquica, autoritário, patriarcal e racista (Moura, 1977). Portanto, o mercado de trabalho está atravessado pelas determinações da divisão sexual e étnico-racial do trabalho. Tal configuração pode ser facilmente visualizada na estrutura do mercado de trabalho, sendo que a inserção de mulheres ocorre de forma desigual, com rebaixamento salarial ainda que da mesma ocupação exercida pelas pessoas do sexo masculino (Cisne; Santos, 2018). Além da divisão sexual do trabalho, o racismo estrutural e cultural expõe as mulheres negras ao desempenho de funções de menor status salarial e de reconhecimento social, em geral, a população negra desempenha ocupações informais, sendo que às mulheres negras, reserva-se o trabalho de domésticas, mantendo a histórica dependência para com as famílias brancas (Gonzáles, 1984).

O trabalho na esfera da reprodução social historicamente foi designado às mulheres, assim, a partir da pandemia de COVID-19, a concentração das atividades de cuidados de filhos, idosos, pessoas com deficiências, de higiene, alimentação, entre outros, interatuaram para a sobrecarga feminina. Além do aumento da violência doméstica contra as mulheres.

Quando você coloca isso de você trabalhar... (latidos), minhas cachorras, elas sempre latem quando eu estou aqui (risada, grito de criança), só um minutinho... é bom ter essa flexibilidade... ao mesmo tempo, aqui é minha casa e, agora, também o meu local de trabalho, acho importante essas separações, eu entendo... (Girassol, GF, AS/PS, 2020).

No INSS, o que observamos são servidores (não somente assistentes sociais) com queixas de dores osteo musculares (vista a falta de ergonomia); sistemas informatizados com mal funcionamento, equipamentos pessoais ruins (tem gente até comprando computador) e redes de internet precárias; as dificuldades de conciliar os cuidados com os filhos, a casa e o trabalho, em especial as mulheres; queixas importantes de sofrimento emocional, com pessoas iniciando tratamento terapêutico e psiquiátrico após o início do trabalho remoto (Lírio, GF, AS/PS, 2020).

O teletrabalho exige condições de infraestrutura e a organização temporal para o traba- lho em casa, o que geralmente para as mulheres significa conciliar a dupla jornada e papéis de cuidado com filhos, idosos, casa e profissional.

No INSS, as coisas são planejadas em cima da hora, o fluxo de informações é enlouquecedor, as novidades são diárias. [...] tudo é feito sem o devido planejamento ou diálogo com os servidores. Ficou escancarado nesse período como a gestão do INSS, em todos os níveis, possui enorme despreparo para a gestão do trabalho e das pessoas. Há alguns programas de atendimento online com psicólogos, mas não adianta se as condições concretas de trabalho não são resolvidas. Como eu disse para uma amiga, este é o momento em que as chefias de perfil sociopata se divertem (aumentando o assédio) e as chefias omissas ignoram os problemas e fingem normalidade (Lírio,GF, AS/PS, 2020).

Sabe-se que gestores passam a imagem do teletrabalho como associação simples e feliz entre os afazeres da vida pessoal e da sócio reprodução com os objetivos produtivos e da empresa. Tal associação produz uma falsa aparência de unidade entre vida pessoal e trabalho, como se a casa e o ambiente familiar fossem próprios ao trabalho, por conseguinte, exige-se o investimento pessoal em bons computadores, boa rede de internet, no manejo do sistema e o certificado que permite o acesso ao sistema, “[...] para acessar o sistema você tem que comprar um certificado digital, é igual um pen drive que você compra e você consegue acessar o sistema remotamente" (Camélia, GF, AS/PS, 2020). O certificado digital para acesso ao sistema, no início da instituição do teletrabalho, foi colocado como responsabilidade dos próprios servidores e servidoras “[...] eu comprei, foi em torno de 200 reais, eu paguei com o meu dinheiro" (Camélia, GF, AS/PS, 2020). Todos esses fatores associados às dificuldades próprias do processo de trabalho e de funcionamento do sistema: "Nós enfrentamos um sistema que não funciona, vai e volta" (Rosa, GF, AS/PS, 2020) reproduzem impactos objetivos e psicossociais no trabalho.

As entrevistas evidenciam que a gestão do INSS promove intensa pressão para a alta produtividade e cumprimento de metas, que já 
existiam, mas que foram intensificadas a partir do teletrabalho, sem muita nitidez das condições objetivas de infraestrutura e de assimilação dos processos para a efetividade da produtividade exigida, impõe uma reunião mecânica de disposições a serem alcançadas. Criam respostas simétricas do trabalho, que, ao ser feito em casa, estabelece a lida que o trabalhador e trabalhadora enfrentam para conciliar ambientes tão díspares, todavia, tratados como uma reunião simples e concertada de interesses.

Também foi evidenciado que o INSS não prima por processos de qualificação, tampouco diálogos com os funcionários e funcionárias, além disso, frequentemente são criadas normativas que devem ser seguidas no dia a dia de trabalho, todavia, sem a qualificação adequada, geram tensões, estresses e adoecimentos.

O trabalho na PS está dotado de uma complexidade que envolve o manejo das normas, regras para a análise das demandas, as quais trazem as marcas do mercado de trabalho de traços transitórios e de rudimentar segurança (Lourenço et al.,2017). De modo sumário, o trabalho precário, sem garantias e descontínuo persiste na ausência do direito em momentos de invalidez, velhice e busca pelos benefícios previdenciários.

Dessa forma, há um fato muito significativo do conteúdo desse trabalho, compreendido a partir das entrevistas com as AS, que é o seguinte: o direito à PS comparece limitado a uma concepção dogmática, que tem como సิ pressuposto central o quadrante legal de se- gurado, além da rigidez institucional e do excesso de documentações exigidas. Cabe ao tra\& balhador ou trabalhadora da PS evitar fraudes † e não permitir erros na concessão dos benefí$\dot{2}$ cios. Especulações dessa ordem geram tensões, கீ medo, conflito ético, estresse, angústia e ado$\vec{i}$ ecimentos (Seligmann-Silva, 2011; Lourenço, 2016, Ribeiro, 2005; Barreto, 2019).

Então, o que o INSS tem feito? Ele trabalha com metas, né? Na verdade, foi feita uma proposta de noventa pontos para os servidores que tiverem interesse em participar das Centrais de Análise e aí, depois disso, veio ainda a possibilidade de dois programas: o semipresencial, a pessoa vai três vezes na semana na Agência, na unidade, trabalha na unidade por quatro horas, tem que fazer o registro do ponto por quatro horas e o restante trabalha em casa; e tem a outra modalidade de trabalhar só em casa (Girassol, GF, AS/PS, 2020).

Durante a pandemia de COVID-19, a PS reordenou o trabalho para as modalidades de teletrabalho, semi-presencial ou híbrido e a permanência nas Agências, mas sem o atendimento ao público, em todas essas formas de trabalho o elemento estruturante passa a ser a produtividade, que anteriormente à pandemia, assumia mais um viés coletivo, uma vez que, além da avaliação individual, toda a Agência era avaliada, a partir da pandemia as avaliações se tornam essencialmente individuais, sendo o trabalho medido por pontuações segundo a atividade realizada.

Paradoxos são evidenciados nos depoimentos coletados. De um lado, um discurso que aborda o teletrabalho e o trabalho semipresencial como se resumissem a novidades positivas, entre a categoria de trabalhadores e trabalhadoras da PS. De outro, um ambiente institucional marcado pelo clima de ameaça tanto a quem não cumprir as pontuações exigidas, quanto a quem não aderir o trabalho por pontuação; segundo as entrevistadas as ameaças vão desde as avaliações pela instituição, com perda das bonificações que compõe os salários na PS até a obrigatoriedade do funcionamento das APS, em jornada de oito horas diárias, interrompendo a possibilidade de turno estendido, de seis horas diárias. O salário na PS, embora relativamente alto quando comparado com o salário-mínimo vigente no País, constitui-se em grande parte de gratificações, que até então vinculavam-se às metas atingidas individualmente e pela Agência. A partir do teletrabalho, ou mesmo do trabalho híbrido, as metas tornam-se individuais por meio do alcance dos bônus, cada serviço tem um tipo de pontuação e ao final o servidor ou servidora tem que ter cumprido determinada pontuação "[...] cada serviço tem um ponto, né? Alterou essa ques- 
tão do tempo, antes a gente tinha tempo determinado para realizar o atendimento, agora, alteraram para pontuações" (Camélia, GF, AS/PS, 2020). A gestão do INSS vem trabalhando com a produtividade do trabalho "desde, mais ou menos, 2010, quando se implementou os tais mapas estratégicos, que estabelecia o tempo que cada servidor poderia gastar para fazer um atendimento, por exemplo, para fazer a análise de uma pensão tinha 30 minutos, para fazer a análise de outro benefício tinha 45 minutos, cada benefício tinha o seu tempo" (Narciso, Oficina, AS/PS, 2017).

As medidas de gestão vêm também numa perspectiva de reduzir a previdência e o acesso, enfim...., mas teve essa adesão de parte considerável dos servidores, o último dado que a gente teve, nós temos mais de 20 mil servidores no INSS e cerca de sete mil servidores aderiram a esse programa de bonificações (Camélia, GF, AS/PS, 2020).

A instituição de metas no trabalho não é um processo isolado, mas está acompanhada de formas de avaliação, bônus, premiações e, de outro lado, ameaças (Gaulejac, 2007; Barreto, 2019). O não cumprimento de metas na PS, ainda que, nesse período de pandemia de COVID-19, tem sido acompanhada de ameaças, de forma velada e direta, tais como: 1) retirada de bonificações que compõem os salários, num contexto de ausência de reposição salarial. Essas bonificações funcionam como um mecanismo individual de aumento salarial; 2) retornar para o atendimento ao público e 3) fim do funcionamento das APS com turno estendido e a exigência do cumprimento da jornada de oito horas diárias de trabalho.

Os ganhos salariais ficam atrelados às bonificações segundo as metas atingidas e a um sistema poderoso de avaliação, pois toda vez que se institui metas a serem alcançadas, instituem-se também os mecanismos de avaliação e controle, bem como um sistema de eliminação de quem não consegue atingir as metas estipuladas (Gaulejac, 2007), no caso específico da PS, o retorno ao atendimento público, comparece como "castigo". Interroga-se a respeito do sentido do trabalho na PS. "Toda a questão é que o atendimento ao público aparece como castigo, né. E por que é um castigo? De fato, atender ao público não é fácil para ninguém, é um serviço que demanda relações com as pessoas, a gente tem que ter uma qualificação para isso (Girassol, GF, AS/PS, 2020).

O cumprimento de metas não é a soma de ações isoladas, mas é, sobretudo, o engajamento nas técnicas, na cultura e objetivos da organização, que produz uma verdadeira interpenetração, um entrelaçamento dos graus de individualidade da pessoa que trabalha com os da instituição (Seligmann-Silva, 2011; Barreto, 2019). A partir desse processo, trabalhadores e trabalhadoras assumem como responsabilidade pessoal, tendo em vista a função, única e comum, o alcance das metas que aparecem dentro de certa reciprocidade, enquanto ganhos salariais. Todavia, não se confirma como sentido do trabalho ao longo da experiência funcional e da vida, assim, comparece mais como destruição do sentido elou da instalação do mal-estar no trabalho, marcado pelo paradoxo de mais autonomia num contexto maior controle (Gaulejac, 2007).

Os depoimentos das AS entrevistadas evidenciam o teletrabalho a partir de inúmeros obstáculos, na maioria das vezes, enfrentados individualmente. "É um trabalho sozinho, sem trocas, quando você está na Agência, a gente fala o que está acontecendo, conversa etc., em casa, não tem nada disso. É cada um na sua casa, e cada um na sua" (Rosa, GF, AS/PS, 2020). O teletrabalho é o aperfeiçoamento do processo de enfraquecimento da solidariedade coletiva e dos ganhos do trabalho. Trata-se de um processo que individualiza ainda mais o trabalho, ainda que as ligações com o trabalho coletivo permaneçam, mas a sua operacionalização distante do espaço coletivo de trabalho e permeado pelo ciberespaço, ao mesmo tempo, pelo espaço doméstico e vida privada expõe profunda desarticulação dos trabalhadores e trabalhadoras enquanto classe, como se sabe, individualmente, o pleito de reivindicações 
por melhores condições de trabalho e concursos públicos se torna uma tarefa hercúlea e essencialmente desarticulada. Ademais, o processo em curso de reestruturação da PS supõe a redução das Agências da Previdência Social e até mesmo da autarquia PS, pois o horizonte, desde a contrarreforma da PS é a capitalização e o fim do sistema de solidariedade intergeracional que vinha integrando o modelo de PS, mas que foi gravemente direcionada para a capitalização individual.

\section{CONSIDERAÇÕES FINAIS}

A pandemia de COVID-19 e respectivas medidas de isolamento social apresentam justificativas exaustivas para a predisposição do teletrabalho, embora seu molde no INSS é anterior à pandemia, especialmente, ante a ausência de concursos públicos. Trabalhadores e trabalhadoras do setor administrativo da PS foram inseridos no sistema de teletrabalho para a análise de benefícios, com determinações da sua ocorrência definitiva após a pandemia. Profissionais das áreas da enfermagem, médicos, psicologia, terapia ocupacional e serviço social têm realizado serviço de plantão, serviço de atendimento telefônico, com horário fixo, presencial, semipresencial ou remoto. Todavia, a natureza do seu trabalho, o atendimento presencial, não se conforma na modalidade do teletrabalho e fica $\overrightarrow{\mathcal{N}}$ o questionamento dos encaminhamentos desse i trabalho, especialmente, quando do retorno no 월 “novo normal” (Camélia, GF, AS/PS, 2020).

Nesse momento, para o serviço social, A há imensa insegurança: "Dentro do Serviço ¿. Social, vivemos um ineditismo da situação, लि que nos traz angústia dobrada por nosso fazer $\vec{*}$ profissional demandar essencialmente o contato com o público. Temos visíveis dificuldades para achar soluções e mesmo pensar como será o "novo normal" que chega em um futuro não tão distante (Camélia, GF, AS/PS, 2020).

Especulações do teletrabalho indicam a sua filiação aos benefícios de não sair de casa, o que tem que ser analisado com mais vagar. Há um valor a ser considerado em termos de tempo, de maior organização do uso desse tempo, maior autonomia e isso deve ser reconhecido.

Obstáculos quanto às condições materiais de trabalho, de conciliação do ambiente doméstico com o trabalho, de manejo do sistema e das normas, que são editadas com frequência, individualização do trabalho, e distanciamento do coletivo de trabalhadores e trabalhadoras, imposição do alcance de metas, como o atual modelo de produtividade do trabalho por meio de pontuações, ameaças, perda da solidariedade coletiva, ausência de concursos públicos, em consequência, perda de direitos, entre outros, constituem alguns dos elementos negativos do teletrabalho.

O teletrabalho, substancialmente, se vincula às contingências geradas pelas transformações tecnológicas combinando-se à prática do trabalho remoto com o acesso aos serviços e benefícios previdenciários também na forma remota. Para além dessa transformação de cunho mais tecnológico existem as imensas mudanças provocadas pela aprovação da contrarreforma da PS ocorrida em 2019 e pela revisão frequente dos benefícios previdenciários (Souza; Anunciação, 2020). Essas medidas impactam diretamente o acesso ao direito e o processo de trabalho na PS, que vem intensificando os mecanismos de análises e controle das solicitações de benefícios, dos documentos exigidos, em um contexto marcado pela ausência de concurso público e de quadro reduzido de funcionários e funcionárias, tendencialmente intensifica-se o trabalho a tal ponto de gerar o mal-estar no trabalho.

As questões de saúde foram evidenciadas nos vários depoimentos em razão da insatisfação das cobranças da instituição sem o respaldo necessário à execução do trabalho, o que também foi visto como desrespeito. $\mathrm{O}$ acesso à informação e a ausência de diálogos da instituição para com o quadro de servidores e servidoras comparecem como razões para o descontentamento, irritabilidade e estresse, como mencionado "tudo 
chega de última hora”. O funcionamento do sistema on line também foi caracterizado como fator de atrasos do serviço, assim, se o sistema cai, esse trabalho fica parado e acumula para ser feito em outro momento, inclusive até altas horas da noite, dada a necessidade de se atingir determinada pontuação, conforme especificações de bônus a ser acrescido nos salários e nas avaliações individuais dos servidores e servidoras, portanto, contribui para intensificar o trabalho e elevar a jornada de trabalho.

O que é certo é que o teletrabalho é funcional às medidas de exacerbação do neoliberalismo e da gestão do trabalho por produtividade, o que isso quer dizer? O trabalho em casa e o trabalho remoto, a um só tempo, são funcionais à noção de redução de custos e de direitos, bem como a fragilização da solidariedade de classe, porque embora componha um trabalho coletivo, se efetiva de forma individual, parcial e subordinada. "O trabalho em casa tem uma questão fundamental que é a ausência do contato, de encontros com outros trabalhadores e trabalhadoras e das relações afetivas com o trabalho. Você não interage, não toma café, não cumprimenta. É um trabalho solitário. Sem cheiro, sem abraços, sem curiosidades com o outro, sem os laços e amizade. Como é isso para a subjetividade?” (Rosa, GF, AS/PS, 2020).

Recebido para publicação em 23/10/2020 Aceito para publicação em 1\%/10/2021

\section{REFERÊNCIAS}

ABÍLIO, Ludmila Costhek. Da revenda dos produtos da Natura ao motorista Uber: a generalização do trabalho informal. Fórum de Debates e Entrevistas. 2019. Disponível em: https://www.youtube.com/watch?v=9Qx VUWMl6w\&t=459s Acesso em: 20.06. 2020 .

AMITRANO, C; MAGALHÃES, LCG; SILVA, MS. Medidas de Enfrentamento dos efeitos econômicos da pandemia Covid-19: panorama internacional e análise dos casos dos Estados Unidos, do Reino Unido e da Espanha. IPEA. 2559.Texto para Discussão. Brasília: DF. Maio, de 2020. Disponível em: https://www.ipea.gov.br/portal/index. php?option $=$ com content\&view $=$ article\&id $=35572 \&$ Ite $\operatorname{mid}=448$. Acesso em: 17.06.2020.

ANDERSON, P. Balanço do neoliberalismo. In: SADER Emir e GENTILI, Pablo. Pós- neoliberalismo: as políticas sociais e o Estado democrático. Rio de Janeiro: Paz e Terra, 1995. p. 9-23.

ANTUNES, Ricardo. O Privilégio da Servidão: o novo proletariado de Serviços na era digital. São Paulo: Boitempo; 2018.

BARRETO, Margarida. Assédio moral e reforma trabalhista: entrevista com Margarida Barreto. Katalyses. v.22 no.3. Florianópolis Sept./Dec. 2019. Disponível em: $\quad$ http://www.scielo.br/scielo.php?script=sci arttext\&pid $=$ S1414-49802019000300641. Acesso em: 28.02. 2020

BRASIL. Ministério da Saúde. Boletim Epidemiológico Especial n.29: doença pelo coronavírus, COVID-19. Semana Epidemiológica 35 (23 a 29/08), 2020 a. Disponível em: https://antigo.saude.gov.br/images/pdf/2020/ September/02/18h-Boletim-epidemiologico-COVID-29final.pdf. Acesso em: 02.09. 2020.

BRASIL. Portaria 10.736, 27 de abril, de 2020. Diário Oficial da União, 2020b. Disponível em: https://www. in.gov.br/web/dou/-/portaria-n-10.736-de-27-de-abrilde-2020-254215694. Acesso em: 27.08. 2020.

BRASIL, SECRETARIA DE PREVIDÊNCIA. Contratação de 8.230 servidores temporários é autorizada pelo Ministério da Economia,2020c. Disponível em:<https://www.gov. br/previdencia/pt-br/assuntos/noticias/previdencia/inss/ contratacao-de-8-230-servidores-temporarios-e-autorizadapelo-ministerio-da-economia > . Acesso em: 27.08.2020.

BRASIL DE FATO. Empresários obrigam trabalhadores a se ajoelharem em protesto contra quarentena na $\mathrm{PB}$, 28 abril 2020. Disponível em: https://www.brasildefato. com.br/2020/04/28/na-pb-empresarios-protestam-contraquarentena-e-obrigam-trabalhadores-a-se-ajoelhar. Acesso em: 05.08. 2020.

CAMUS, A. A Peste. Rio de Janeiro, RJ: BestBolso, 2014.

CISNE, Mirla; SANTOS, Silvana. Feminismo, diversidade sexual e serviço social. São Paulo: Cortez, 2018.

COLETTA, RD. 'Bolsonaro diz que Brasil pode deixar OMS se organização não abandonar ‘viés ideológico’. Folha de São Paulo. Saúde. Disponível em:https://www1.folha. uol.com.br/equilibrioesaude/2020/06/bolsonaro-diz-quebrasil-pode- deixar-oms-se-organizacao-nao-abandonarvies-ideologico.shtml. Acesso em: 18.06.2020.

COLON, L. PF identifica Carlos Bolsonaro como articulador em esquema criminoso de fake news. Investigação sigilosa é conduzida em inquérito no STF (Supremo Tribunal Federal). Folha de São Paulo. Poder, 25 de abril de 2020. Folha de São Paulo. Disponível em:https://www1.folha. uol.com.br/poder/2020/04/pf-identifica-carlos-bolsonarocomo-articulador-em-esquema-criminoso-de-fake-news. shtml. Acesso em: 15.05.2020.

DARDOT, Pierre; LAVAL, Cristhian. A nova razão do mundo: Ensaios sobre a sociedade neoliberal. São Paulo: Boitempo, 2017.

DEJOURS, Christophe. A loucura do trabalho: estudo de psicopatologia do trabalho. São Paulo: Cortez, 1987.

DEJOURS, Christophe. A banalização da injustiça social. Rio de Janeiro: Fundação Getúlio Vargas, 2006.

FELLET, J. 'Vírus chinês': como Brasil se inseriu em disputa geopolítica entre EUA e China sobre pandemia. BBC News Brasil, em São Paulo, 19, mar., 2020. Disponível em: https://www.bbc.com/portuguese/brasil-51963251. Acesso em: 02.05. 2020

FERNANDES, Victor Cezar. A distopia empírica do capitalismo digitalizado: novas formas de controle, reordenamento econômico, político e social no marco da Indústria 4.0. In: SOUZA, Edvânia Ângela de.; SILVA, Maria Liduína Oliveira. Trabalho, questão social e Serviço Social: a autofagia do capital. São Paulo: Cortez, 2019. p. 61-73. 
IBGE. Instituo Brasileiro de Geografia e Estatística. PNAD CONTINUA: taxa de desocupação é de $14,4 \%$ e taxa de subutilização é de $30,6 \%$ no trimestre encerrado em agosto de 2020. Agência IBGE Notícias, 2020a. Disponível em: <https://agenciadenoticias.ibge.gov.br/agencia-salade-imprensa/2013-agencia-de-noticias/releases/29322pnad-continua-taxa-de-desocupacao-e-de-14-4-e-taxade-subutilizacao-e-de-30-6-no-trimestre-encerrado-emagosto-de-2020 >. Acesso em: 30.10. 2020.

IBGE. Instituo Brasileiro de Geografia e Estatística. Relatório da Pesquisa sobre Trabalho Remoto no IBGE 2020. Gerência de qualidade estatística /COMEQ/DPE. Gerência de desenvolvimento de pessoas/CRH/DE. Gerência de sistemas populacionais e sociais /COADS /DI. 2020b. Disponível em: <https://biblioteca.ibge.gov.br/index. $\mathrm{php} /$ biblioteca-catalogo view $=$ detalhes\&id $=2101751>$. Acesso em: 27.08.2020.

IBGE. Instituo Brasileiro de Geografia e Estatística. PNAD - COVID19: 21,6\% das pessoas que realizaram testes para coronavírus até agosto testaram positivo. Agência IBGE Notícias. Disponível em: <https://agenciadenoticias.ibge.gov.br/agenciasala-de-imprensa/2013-agencia-de-noticias/releases/28936-pnadcovid19-21-6-das-pessoas-que-realizaram-testes-para-coronavirusate-agosto-testaram-positivo >. Acesso em: 20.08. 2020.

GAULEJAC, Vicent. Gestão como doença social: ideologia, poder gerencialista e fragmentação social. Aparecida: Ideias e Letras, 2007.

GONZÁLES, L. Racismo e sexismo na cultura brasileira. Revista Ciências Sociais Hoje, Anpocs, 1984, p. 223-244.

GOVERNO DE SÃO PAULO. SP CONTRA o novo coronavírus. Sistema de monitoramento inteligente do governo de São Paulo atualiza diariamente índice de adesão ao isolamento social no Estado. Disponível em:https:// www.saopaulo.sp.gov.br/coronavirus/isolamento/ Acesso em: 10.07. 2020.

LOURENÇO, Edvânia Ângela de Souza, et.al. Condições de trabalho de assistentes sociais da área da saúde e repercussões psicossociais. Saúde e Sociedade, São Paulo, v. 28, n. 1, p. 154-168, 2019. Disponível em: https://doi.org/10.1590/s010412902019180675. Acesso em: 12.06. 2019.

LOURENÇ, Edvânia Ângela de; LACAZ, Francisco Antonio de Castro; GOULART, Patrícia Martins. Crise do capital e o desmonte da Previdência Social no Brasil. Serviço Social e Sociedade. 2017; (130), p. 467-486.

LOURENCO, Edvânia Ângela de. (Org.). Saúde do/a trabalhador/a e Serviço Social: estudos da relacão trabalho e saúde no capitalismo contemporâneo. São Paulo: Papel Social, 2016.

MACHADO, R. Polícia indicia 3 após agressão de grupo bolsonarista contra enfermeiros em protesto: Suspeitos - por ação em Brasília vão responder por infrações de خิ menor poder ofensivo. Folha de São Paulo. https://www1. จ folha.uol.com.br/poder/2020/05/policia-indicia-3-apos$\infty$ agressao-de-grupo-bolsonarista-contra-enfermeiros-em\% protesto.shtml. Acesso em: 01.06. 2020.

MARX, K. O Capital: crítica da economia política: Livro I: o - processo de produção do capital. São Paulo: Boitempo, 2006.

I MIRANDA,Wildredo, deManágua.OPRESIDENTESUMIU. - Na Nicarágua, amor e fé são os remédios do governo contra 2 a pandemia. Piauí, edição 164, maio de 2020. Tempos f da Peste. Disponível em: https://piaui.folha.uol.com.br/ $>$ materia/volta-ao-mundo/. Acesso: 31.05.2020.

8 MOURA, Clóvis. O negro, de bom escravo a mau cidadão? Rio de Janeiro: Conquista, 1977.

क N NOGUEIRA, Cláudia Mazzei. A feminização no mundo do I trabalho: entre a emancipação e a precarização. Campinas, SP: Autores Associados, 2004.

ONOFRE, R; GARCIA, L. Mandetta diz que quarentena total será desastre e critica carreatas Ministro descartou isolamento vertical como forma de combater o coronavírus. Folha de São Paulo. Saúde, 28, de março, de 2020. Disponível em: https:// www1.folha.uol.com.br/equilibrioesaude/2020/03/mandettadiz-que-quarentena-total-e-desastre-e-critica-carreatas. shtml. Acesso em: 15.05.2020.

RIBEIRO, H. P. O juiz sem a toga: um estudo da percepção dos juízes sobre trabalho, saúde e democracia no judiciário. Florianópolis: Lagoa, 2005.

ROY, A. De Nova Delhi, A pandemia é um portal. Como o coronavírus ameaça a Índia - e o que o país, e o mundo, deveriam fazer depois. Piauí, edição 164, maio de 2020. Tempos da Peste. Disponível em: https://piaui.folha.uol. com.br/materia/volta-ao-mundo/. Acesso: 31.05. 2020.

SCHWAB. K. A Quarta Revolução Industrial. São Paulo: Edipro. 2016.

SANTOS, Apa, et. al. População negra e Covid-19: reflexões sobre racismo e saúde. Estudos Avançados. 2020, v. 34, n. 99, p. 225-244. https://www.scHYPERLINK https://www.scielo.br/scielo.phpscript=sci abstract\&pid So10340142020000200225\&lng = pt\&nrm = is o "ielo.br/scielo.phpscript=sci_abstractHYPERLINK "https://www.scielo.br/ _ scielo.phpscript=sci abstract\&pid = S010340142020000200225\&lng=pt\&nrm = iso"\&HYPERLINK "https://www.scielo.br/scielo.phpscript= sci abstract\&pid $=$ S010340142020000200225\&lng $=$ pt\&nrm $=$ iso" pid = S010340142020000200225 HYPERLINK "https://www.scielo.br/scielo.phpscript $=$ sci abstract\&pid = S010340142020000200225\&lng = pt\&nrm=iso"\&HYPERLINK "https://www. scielo.br/scielo.phpscript $=$ sci abstract\&pid $=$ S $010340142020000200225 \& \operatorname{lng}=\mathrm{pt} \& \mathrm{nrm}=$ iso"lng=ptHYPERLINK "https://www.scielo. br/scielo.phpscript =sci abstract\&pid = S010340142020000200225\&lng $=$ pt\&nrm $=$ iso "\&HYPERLINK "https://www.scielo.br/scielo.phpscript =sci abstract\&pid= S010340142020000200225\&lng = pt\&nrm =iso" $\mathrm{nrm}=\mathrm{io}$

SELIGMANN-SILVA, E. Trabalho e desgaste mental: o direito de ser dono de si mesmo. São Paulo: Cortez, 2011.

SHUMAKER, L, CHIACU, D. EUA passam de 130.000 mortes por Covid-19 após aumento recorde de casos. Reuters. Disponível em: https://br.reuters.com/article/ topNews/idBRKBN24724J-OBRTP. Acesso em: 10.07. 2020.

SOUZA, E. A. de. Indústria 4.0: serviço social no sistema previdenciário em tempos de pandemia covid-19. Katályses, 2021 (no prelo).

SOUZA, Edvânia Ângela de; ANUNCIAÇÃO, Luís. Narrativas de sofrimento e trabalho profissional do Serviço Social da Previdência Social em Tempos de Indústria 4.0. Serviço Social e Sociedade, São Paulo: Cortez, n. 138, mayago, 2020, p. 2015-241.

VALFRÉ, Vinícius; SOARES, Jussara. Outdoor que tinha Bolsonaro como garoto-propaganda da cloroquina é retirado. O Estado de S. Paulo, 10 ago. 2020. Disponível em:.https://politica.estadao.com.br/noticias/geral, outdoorcom-bolsonaro-como-garoto-propaganda-da-cloroquina-eretirado,70003394107. Acesso em: 30 out. 2020.

WALLACE, Rob. Pandemia e agronegócio: doenças infecciosas, capitalismo e ciência. Elefante, 2020.

WHO. World Health Organization. Coronavirus disease (COVID-19). Situation Report - 206 Data as received by WHO from national authorities by 10:00 CEST, 13 August 2020b. Disponível em: https://www.who.int/docs/defaultsource/coronaviruse/situation-reports/20200813-covid-19sitrep-206.pdf?sfvrsn=bf38f66b_6. Acesso: 15.08 .2020 .

ZIZEK, S. Coronavirus es un golpe al capitalismo al estilo de 'Kill Bill' y podría conducir a la reinvención del comunismo. In:AMADEO, Pablo (Org.). Sopa de Wuhan: pensamiento contemporáneo en tiempos de pandemia. ASPO (Aislamiento Social Preventivo y Obligatorio). 1. a edición: marzo 2020.

ZUBOFF, Shoshana. Big Other: capitalismo de vigilância e perspectiva para uma civilização de informação. In: BRUNO, Fernanda et. al.(Orgs). Tecnopolíticas da Vigilância: perspectivas da margem. São Paulo: Boitempo, 2018, p. 17-68. 


\section{THE COVID-19 PANDEMIC AND TELEWORKING IN SOCIAL SECURITY (PS)}

\author{
Edvânia Ângela de Souza
}

There is a very significant fact that interacts for the transfer of work, both from public and private institutions, to the virtual environment, telework, which is the pandemic caused by the new coronavirus, COVID-19. Measures to fight the pandemic foresee social distancing, therefore, the work, in some companies, has been carried out remotely, however, the conditions for its occurrence precede the pandemic and are linked to technological development and neoliberal measures. The aim is to discuss remote work in Social Security (PS) in Brazil. Therefore, semi-structured interviews were carried out with social insurance (PS) analysts. It is evident that telework results from a dialectical process, which implies greater flexibility in working hours and, paradoxically, in the absence of adequate conditions, in an equation of high demand, few workers, requirement to meet targets, responsibility for adequate conditions for work carried out outside the business environment, greater individualization and overload of women, as a result, work intensification, stress and mental suffering related to work.

Keywords: Covid-19. Telework. Social security. Worker's health.

\section{LA PANDÉMIE COVID-19 ET LE TÉLÉTRAVAIL DANS LA SÉCURITÉ SOCIALE (PS)}

\author{
Edvânia Ângela de Souza
}

Il y a un fait très significatif qui transfère le travail des institutions publiques et privées vers les espaces domestiques, qui est la pandémie causée par le nouveau coronavirus, Covid-19. Les mesures de lutte contre la pandémie prévoient une distance sociale, par conséquent, le travail a été effectué à distance, mais sa manifestation précède la pandémie et est liée au développement technologique et aux mesures néolibérales. L'objectif est de discuter du travail à distance dans la sécurité sociale (PS) au Brésil. Des entretiens semi-structurés ont été menés avec des analystes de la sécurité sociale du PS. Il est évident que le télétravail résulte d'un processus dialectique, qui implique une plus grande flexibilité des horaires de travail et, paradoxalement, en l'absence de conditions adéquates, dans une équation de forte demande, peu de travailleurs, une exigence pour atteindre les objectifs, responsabilité de conditions adéquates de travail à domicile, individualisation et, par conséquent, augmentation de la surcharge de travail, du stress et des souffrances mentales liées au travail.

Mots CLÉs: Covid-19. Télétravail. Sécurité sociale. Santé du|travailleur $\backslash a$

Edvânia Ângela de Souza - Assistente Social, professora doutora do Departamento de Serviço Social da Faculdade de Ciências Humanas e Sociais (FCHS), Universidade Estadual Paulista em Franca. Professora Colaboradora do Programa de Pós-Graduação em Serviço Social e Políticas Sociais (PPGSSPS da UNIFESP-Baixada Santista). Principais publicações: SOUZA, Edvânia Ângela de; CELIS, Ariana; INÁCIO, José Reginaldo. Vidas ameaçadas: diálogos a respeito da pandemia de COVID-19, trabalho, serviço social e saúde do trabalhador e da trabalhadora. Campinas: Papel Social, 2021. 268 p.; SOUZA, Edvânia Ângela de; SILVA, M. L. O. Trabalho, questão social e serviço social: a autofagia do capital. São Paulo: Cortez, 2019, v.600. p.249; NAVARRO, V. L.; LOURENÇO, E. Â. S. O Avesso do Trabalho IV: terceirização, precarização e adoecimento no mundo do trabalho. São Paulo: Expressão Popular, 2017, v.900. p.475; LOURENÇO, E. Â. S. Saúde do Trabalhador e da Trabalhadora: estudos da relação trabalho e saúde no capitalismo contemporâneo. Campinas: Papel Social, 2016, v. 500. p. 424. 
